\section{P-45 INSPIRING OUR RETAIL SHOPS TO CONNECT TO HOSPICE CARE PROVISION}

Joanne Polkey, Liz Morgan. Nottinghamshire Hospice, Nottingham, UK

\subsection{6/bmjspcare-2019-HUKNC.69}

Striving to make the links between donating your preloved items at one of our nine charity shops and how this helps to provide hospice care is key to increasing our service provision and working with the general public. Improving this connection at Nottinghamshire Hospice has been the focus for our retail and care teams. Retail staff and shop volunteers have a greater insight into the services our hospice provides by each shop taking on one of the services and dedicating their support to it.

Our shops are a focal point of local communities, they generate a presence for spreading the word about the work the hospice does. We cover a huge geographical area and our primary services are delivering Hospice in your Home nursing care, shops are central to promoting work which is going on in their locality, often behind closed doors in people's homes nearby at the very end of life.

Retail managers have embraced the opportunity to learn more about their chosen service through shadowing, visits and training. The aim being that donors to the shops, the staff and volunteers get to promote with confidence specific elements of the care we provide and see how their donations and time given make a difference in real terms (i.e. income generation).

Shops have provided fantastic window displays detailing the service they are supporting as well as leaflets and advice. In turn shop profits will be turned into care costs for example the shop supporting Hospice at Home will be able to display the number of hours of care they have funded or the number of people supported by their generosity. This will provide a greater effective resource into the community across Nottinghamshire and will be reviewed and evaluated every six months when each shop will choose a new service to support.

\section{P-46 SAFE PLACE SCHEME}

Gemma Allen. The Mary Stevens Hospice, Stourbridge, UK

\subsection{6/bmispcare-2019-HUKNC.70}

Background Safe Places provides people who may be vulnerable, including people with learning disabilities and autism, those living with dementia or who need support and assistance, with a temporary place of safety when out in their local community. It encourages vulnerable people to deal with situations effectively, and to feel confident and safe when out by having a recognisable symbol displayed in windows, identified by users of the scheme.

Aims

- Hospice services and retail stores to be recognised and awarded Safe Places, enabling people with learning disabilities and people living with dementia to feel safe and secure whilst out in their local community;

- Closer working relationships between clinical services and trading sector.
Method

- Work collaboratively with self-advocacy group, get advice and support on implementing the Safe Place scheme;

- Visited retail shops, discussed the programme with store managers and volunteers;

- 'Mystery shop' stores by an Expert by Experience, assessing accessibility, friendliness and helpfulness of staff.

Results Inpatient unit, day services, fundraising department and all stores awarded and listed on Community Information Directory, being first organisation to have all services recognised as 'Safe Places' in the local area.

Conclusion Hospice shops are at the heart of local communities and are places where we are able extend our hospice values of Care, Kindness, and Compassion.

An Expert by Experience said of the programme:

'Safe Places are very important, if you need some support or feel a bit frightened and anxious you can go to a Safe Place and they either give you time to feel less anxious or will call someone you know for you. We need to make sure our Safe Places have kind, welcoming and understanding people so was very happy that the hospice decided to join the scheme.'

\section{Developing and Supporting the Workforce}

\section{P-47 END OF LIFE CARE WORKBOOK FOR SUPPORT AND CARE STAFF}

Sadaf Adnan, Jayne Bargh. Kirkwood Hospice, Huddersfield, UK

\subsection{6/bmjspcare-2019-HUKNC.71}

The Kirklees and Calderdale EOL Training and Education group were successful in a bid for West Yorkshire and Harrogate Excellence Centre funding in order to develop targeted end of life care training and education across care homes in Kirklees and Calderdale. A comprehensive workbook was developed and launched in October 2018, supported by two best practice events. The uptake and interest in the care home workbook has been enormous, with over 100 attendees at the best practice event in Kirklees and 45 attendees at a follow up event held in April 2019. Local CQC managers were keynote speakers at both launch events and have continued to champion the workbook.

The purpose of the workbook is to increase knowledge and awareness of good practice. Local and national information points to the need for earlier identification and pro-active care for people in the last year of life; given that end of life care spans many care settings and sectors. Age UK's End of Life Evidence Review (2013) identifies the need for adequate training and education for care homes.

The workbook was delivered by a collaborative group with involvement from Kirkwood Hospice, Overgate Hospice, Kirklees Council, Calderdale and Huddersfield NHS Foundation Trust and Locala CIC. It was piloted with local care homes.

600 copies of the workbook have been printed so far, with care homes also accessing the resource online. The provision of targeted care home training and education has allowed for local expertise and knowledge to be shared with staff that may not necessarily have engaged with traditional training and education opportunities in the past. 